\title{
Effect of Nanosilica and Bentonite as Mycotoxins Adsorbent Agent in Broiler Chickens' Diet on Growth Performance and Hepatic Histopathology
}

\author{
Abdallah A. Ghazalah ${ }^{1}$, Mamduh O. Abd-Elsamee ${ }^{1}$, Kout Elkloub M. E. Moustafa ${ }^{2}$, \\ Mohamed Abdelrazik Khattab ${ }^{3}$ and Abd-Elrahim A. A. Rehan $2, *$ D \\ 1 Department of Animal Production, Faculty of Agriculture, Cairo University, Giza 12613, Egypt; \\ ghazalah@gmail.com (A.A.G.); mamdouh20466@yahoo.com (M.O.A.-E.) \\ 2 Agriculture Research Center, Institute of Animal Production Research, Ministry of Agriculture, \\ Giza 12619, Egypt; dr.koutelkloub@yahoo.com \\ 3 Department of Cytology and Histology, Faculty of Veterinary Medicine, Cairo University, \\ Giza 12613, Egypt; mabdelrazik@cu.edu.eg \\ * Correspondence: abdou.rehan@yahoo.com; Tel.: +20-10-9993-8833
}

check for

updates

Citation: Ghazalah, A.A.; Abd-Elsamee, M.O.; Moustafa, K.E.M.E.; Khattab, M.A.; Rehan, A.-E.A.A. Effect of Nanosilica and Bentonite as Mycotoxins Adsorbent Agent in Broiler Chickens' Diet on Growth Performance and Hepatic Histopathology. Animals 2021, 11, 2129. https://doi.org/10.3390/ ani11072129

Academic Editors: Paweł Konieczka and Dorota Bederska-Łojewska

Received: 10 June 2021

Accepted: 14 July 2021

Published: 17 July 2021

Publisher's Note: MDPI stays neutral with regard to jurisdictional claims in published maps and institutional affiliations.

Copyright: (C) 2021 by the authors. Licensee MDPI, Basel, Switzerland. This article is an open access article distributed under the terms and conditions of the Creative Commons Attribution (CC BY) license (https:// creativecommons.org/licenses/by/ $4.0 /)$.
Simple Summary: Mycotoxins cause significant economic losses in feed ingredients, nutritional value, feed palatability, and the poultry industry. Thus, there is a need for ways to eradicate or inactivate mycotoxins in chicken feed. The present feeding trial aims to evaluate the use of nanosilica and bentonite to prevent the harmful effects of a mycotoxin-contaminated diet on broiler performance, histopathological, and carcass traits. The obtained results revealed significant improvements in broiler growth performance resulting from the addition of nanosilica at $0.20 \%$ and bentonite at $0.50 \%$. Additionally, the hepatoprotective efficacy of nanosilica was evident at different dose levels. Consequentially, it could be used in broiler's contaminated diets without negatively affecting birds' health.

Abstract: Mycotoxins are toxic secondary metabolites produced by different strains of fungi, such as aspergillus, fusarium, and penicillium that can contaminate feed ingredients or the entire feed of poultry and animals. Mycotoxins can cause many serious complications to both humans and animals due to carcinogenic, mutagenic, and immunosuppressive disorders. Therefore, the present experiment aims to investigate the effect of broiler chickens' diets supplemented with different levels of nanosilica (NS) as an adsorbent agent of mycotoxins on their growth performance and hepatic histopathology. Detectable levels of toxins were present in the feed before feeding, and all levels of mycotoxins were above the normal limit. A total of 180 one-day-old male Arbor Acres broiler chickens were allocated randomly to six treatment groups with three replicates per group, including ten chickens per replicate. The experiment lasted for five weeks, and dietary treatments included control diet and diets with four levels of nanosilica as $0.05 \%, 0.10 \%, 0.15 \%$, and $0.20 \%$ as well as $0.50 \%$ bentonite (fixfin ${ }^{\circledR}$ Dry) diet. Bodyweight, body weight gain, average daily feed intake, and feed conversion ratio were measured weekly. At the end of the fifth week, six chickens per treatment were sacrificed to investigate the effects of NS and bentonite on carcass characteristics and hepatic histopathology. The results showed that providing broiler chickens' diets with an adsorbent agent, such as NS or bentonite, can reduce the side effects of mycotoxins and enhance their growth performance. The best record was achieved with NS at $0.20 \%$, compared with the control group and other dietary treatment groups. Accordingly, $0.20 \%$ of NS could be used in broiler chickens' diets to minimize the harmful effects of mycotoxins.

Keywords: broiler; growth; histopathology; mycotoxins; Nano-Silica 


\section{Introduction}

Mycotoxins are toxic secondary compounds synthesized under specific conditions by certain fungal species that can be present on field crops during harvest, storage, processing, or feeding. The most common mycotoxins are Aflatoxins (AF), Ochratoxin A (OTA), Citrinin, patulin, trichothecenes, Deoxynivalenol (DON), T2 toxin (T2), fumonisins, and Zearalenone (ZEN) [1]. More than 500 mycotoxins could be considered toxigenic. It is estimated that $25-50 \%$ of grains produced around the world are contaminated with mycotoxins to varying degrees, with $5-10 \%$ of them being irreversible, resulting in major economic losses [2,3]. Mycotoxins are considered one of the most serious and dangerous problems affecting poultry and animals, and consequently, affect public health and productivity rates. Therefore, removing mycotoxins from poultry feed is becoming an intractable problem. Currently, there are different methods used to alleviate the side effects of mycotoxins, especially natural sources, such as nanosilica (NS) from rice husk and clay minerals which have been considered as promising adsorbents for highly efficient removal of toxic mycotoxins from animal feeds [4]. The presence of mycotoxins in animal feed may destroy or reduce the nutritional value and palatability of feeds; thus, it makes the animals refuse to eat, grow slower, fall ill easily, and even die [5]. The main problem related to mycotoxincontaminated animal feed is carcinogenic diseases. Carcinogenicity of some mycotoxins occurs when the toxicity passes unaltered through metabolic processes and accumulates in the tissues, causing an array of metabolic disturbances and, consequently, poor animal productivity [1]. Ducks are the most susceptible to mycotoxicosis in poultry, followed by turkeys, quails, broilers, and layers. Symptoms include fatty livers, kidney diseases, leg and bone deformities, decreased weight gain and productivity, immunosuppression, small and poor-quality eggs, and pigmentation issues [6].

For the detoxification and decontamination of feed with mycotoxins, different physical, chemical, and biological methods are used, including eliminating mycotoxins from contaminated feed ingredients, decreasing the bioavailability of such mycotoxins in the gastrointestinal tracts of animals, or directly degrading mycotoxins in feed.

Accordingly, some suggested approaches include using adsorbent agents, chemical treatment, and several microbial species that have been identified for their ability to biotransform mycotoxins into less toxic forms [7].

Many types of mycotoxin binders are used as a feed supplement to alleviate toxicity in the feed. Bentonites and zeolites are commonly used as feed additives due to their good cation exchange reactions and opposite polarity [8,9]. However, the abovementioned mycotoxin adsorbents often bind to other minerals and vitamins present in the diet rendering them inactive. Although conventional methods are constantly improving, recent research findings are looking for innovative solutions. Nanotechnology has the potential to provide some solutions since the possible applications of nanoparticle ingredients as feed additives are believed to be more effective to minimize the health effects of mycotoxins. Nanotechnology approaches appear to be promising, compelling, and low-cost ways to reduce the side effect of mycotoxins on animals' health. Aluminum silicate and other nanoclay types have been introduced as unique additives possessing sizeable surface area, higher porosity, strong cation exchange activities, and more active sites, which interact with mycotoxins [10]. There are two types of nanoparticles, namely natural and synthetic ones [11]. The synthetic nanoparticles are synthesized, either by mechanical grinding, engine exhausts, and smoke, or by physical, chemical, biological, or hybrid methods [12]. Clay minerals are used in poultry nutrition for several reasons, including toxin binding [13], improvement of the enzymatic activity in the small intestine [14], and control of ammonia emission into the environment [15]. In addition, natural clays could change GIT enzymatic secretion by raising the GIT fluids' $\mathrm{pH}$ [16]. In the digestive tract of poultry fed a sepiolitesupplemented diet, increased secretion of digestive enzymes was attributed to a decrease in digesta viscosity [17].

The objectives of the current study were to determine the efficacy of using new strategies to ameliorate the toxic effects of mycotoxins in broiler chickens' diets supplemented 
with NS as an adsorbing agent of mycotoxins by assessing the growth performance of broiler chickens and liver hematology.

\section{Materials and Methods}

\subsection{Ethical Approval}

The Institutional Animal Care and Use Committee of Cairo University approved the experimental protocol used in this study with approval reference number CU II F 321.

\subsection{Experimental Chickens, Design, and Management}

A total of 180 one-day-old male Arbor Acers broiler chickens of similar body weight were distributed randomly into six treatment groups, with three replicates for each group containing ten chickens. Birds were housed in galvanized wire cage batteries (10 birds per $\mathrm{m}^{2}$ ). Feed was provided ad libitum and freshwater was automatically available all time through stainless steel nipples. Birds were raised in a semi-closed house. Room temperature was controlled and thermostatically regulated by two heaters. During the first week, the room temperature was set at $33^{\circ} \mathrm{C}$, gradually reduced by $3{ }^{\circ} \mathrm{C}$ every week until it reached $25^{\circ} \mathrm{C}$. Lighting was available $24 \mathrm{~h}$ for the first three days of the trials. Then, the lighting schedule was $18 \mathrm{~h}$ of light, $6 \mathrm{~h}$ of dark daily during the whole experimental period. In this experiment, birds were vaccinated against avian flu, New-Castle disease, and IB at seven days of age. On the 18th day of age, birds were revaccinated against the New-Castle disease. The trial was carried out at the Poultry Research and Training Unit, Faculty of Agriculture, Cairo University, Giza, Egypt. The trial was carried out during April and May 2019.

\subsection{Materials of Histological Examination}

Samples were taken from three birds per treatment. Dissected liver samples were trimmed and fixed in ten neutral buffered formalin. Samples were dehydrated and processed in serial grades of ethanol, cleared in xylene, and impregnated by Paraplast tissueembedding media. Then, five microns thick tissue sections were cut by a rotatory microtome. Sections were fixed to glass slides and stained by standard hematoxylin and eosin stain for general histological examination [18]. Samples were examined and imaged by using a full HD microscopic imaging system (Leica Microsystems GmbH, Wetzlar, Germany). A microscopic examination lesion score system was performed according to [19].

\subsection{Adsorbing Agent Sources}

The dietary sources of silica used in the current study as an adsorbent agent of mycotoxins were commercial nanoclay (fixfin ${ }^{\circledR}$ Dry) or bentonite (from Kemin company, Belgium). The NS was synthesized from rice husk prepared in the Poultry Nutrition Department Lab, Animal Production Research Insinuate, ARC, Egypt [20].

Corn and soybean meal-based diets were formulated according to the nutritional requirement recommended by the strain catalog of Arbor Acers. Basal diets were formulated for starters (1-14 days old), growers (15-28 days old), and finishers (29-35 days) as shown in Table 1; yellow corn is naturally contaminated with mycotoxins "aflatoxins, ochratoxins, and T-2 toxins" detected in the mash feed before feeding, using Charm Mycotoxin EZ-M Reader from NutriAd International, Belgium.

The experiment lasted for five weeks, and dietary treatments for the control group were provided through diets free of feed additives. Other diets with four levels of NS were $0.05 \%$, $0.10 \%, 0.15 \%$, and $0.20 \%$, and bentonite (fixfin ${ }^{\circledR}$ Dry) represented $0.50 \%$ of the feed diet. For different levels of NS, it was mixed with soybean as a carrier, then added to the diet.

\subsection{Body Weight, Body Weight Gain, Feed Intake, Feed Conversion Ratio, and Slaughter Traits}

Body weights were recorded in all replicates individually at the end of each week. Weights were, therefore, used to calculate the mean body weight. Feed intake was assessed weekly as follows: feed intake $=($ feed offered - feed residual $) /$ number of birds per replicate. Feed Conversion Ratio (FCR) was calculated as feed intake (g)/weight gain (g). Mortality 
was also recorded throughout the trial period. Six chickens per treatment were sacrificed at the end of the fifth week to explore treatment effects on carcass characteristics and hepatic histopathology. The chickens were weighed and slaughtered. Then, the heart, spleen, liver, kidney, bursa of Fabricius, body fat, and gizzard were also weighed. The carcass and organs were estimated as the percentage of live body weight.

Table 1. Composition and calculated analysis of the experimental diets for Arbor Acers broiler during starter (1-14 days old), grower (15-28 days old), and finisher intervals (29-35 days old) ${ }^{1}$.

\begin{tabular}{|c|c|c|c|}
\hline Ingredients & Starter & Grower & Finisher \\
\hline & (1-14 Days) & (15-28 Days) & (29-35 Days) \\
\hline Yellow corn & 51.90 & 57.31 & 62.25 \\
\hline Soybean meal $44 \%$ & 34.99 & 29.60 & 24.25 \\
\hline Corn gluten meal $60 \%$ & 5.00 & 5.00 & 5.00 \\
\hline Soybean oil & 3.28 & 3.82 & 4.45 \\
\hline Limestone & 1.85 & 1.50 & 1.40 \\
\hline Mono calcium phosphate & 1.45 & 1.30 & 1.20 \\
\hline Vitamins and minerals premix ${ }^{2}$ & 0.30 & 0.30 & 0.30 \\
\hline DL-methionine & 0.28 & 0.24 & 0.22 \\
\hline L-lysine hydrochloride & 0.31 & 0.30 & 0.32 \\
\hline L-threonine & 0.09 & 0.08 & 0.06 \\
\hline Sodium chloride & 0.35 & 0.35 & 0.35 \\
\hline Choline chloride $60 \%$ & 0.10 & 0.10 & 0.10 \\
\hline Sodium bicarbonate & 0.10 & 0.10 & 0.10 \\
\hline Total \% & $100 \%$ & $100 \%$ & $100 \%$ \\
\hline \multicolumn{4}{|l|}{ Calculated Composition ${ }^{3}$} \\
\hline Crude protein (\%) & 23.00 & 21.00 & 19.00 \\
\hline Metabolizable energy (Kcal/kg) & 3000 & 3100 & 3200 \\
\hline Crude fiber (\%) & 3.75 & 3.48 & 3.20 \\
\hline Crude fat (\%) & 5.65 & 6.35 & 7.13 \\
\hline Calcium (\%) & 1.00 & 0.87 & 0.80 \\
\hline Available phosphorus (\%) & 0.48 & 0.44 & 0.40 \\
\hline Lysine $(\%)$ & 1.44 & 1.29 & 1.16 \\
\hline Methionine (\%) & 0.50 & 0.51 & 0.47 \\
\hline Methionine + cystine $(\%)$ & 1.08 & 0.99 & 0.91 \\
\hline Threonine $(\%)$ & 0.97 & 0.88 & 0.78 \\
\hline Sodium (\%) & 0.20 & 0.20 & 0.20 \\
\hline
\end{tabular}

${ }^{1}$ According to the nutritional requirement recommended by the strain catalog of Arbor Acers. ${ }^{2}$ Vitamins, for every $1.5 \mathrm{~kg}$, contains vitamins (Vit). A 12,000,000 IU, Vit. D 4,000,000 IU, Vit. E 100,000 mg, Vit. K 3000 mg, Vit. B 2500 mg, Vit. B 5000 mg, Vit. B 5000 mg, Vit. $B_{12} 20 \mathrm{mg}$, nicotinic acid 55,000 mg, pantothenic acid 15,000 mg, folic acid $2000 \mathrm{mg}$, biotin $200 \mathrm{mg}$, choline 400,000 mg, and carrier calcium carbonate up to $1.5 \mathrm{~kg}$. Minerals, for every $1.5 \mathrm{~kg}$, contains iron 80,000 mg, copper $8000 \mathrm{mg}$, zinc 100,000 mg, manganese 120,000 $\mathrm{mg}$, iodine $1000 \mathrm{mg}$, selenium $300 \mathrm{mg}$, cobalt $200 \mathrm{mg}$, and carrier calcium carbonate up to $1.5 \mathrm{~kg}$. ${ }^{3}$ According to the nutritional requirement recommended by the strain catalog of Arbor Acers.

\subsection{Statistical Analysis}

The data collected were statistically analyzed by the least-squares procedure of the General Linear Model (GLM) of the Statistical Analysis System program [21] to study the effect of NS on broiler chickens' performance. To investigate the significance of the means, Duncan's New Multiple Range Test [22] was used and $p$-values less than 0.05 were considered statistically significant.

The model used in the analysis was

$$
Y_{i j}: \mu+T_{i}+\varepsilon_{i j}
$$

where $Y_{i j}$ is the value of the respective variable, $\mu$ refers to the overall mean of the respective variable, $T_{i}$ signifies the effect caused by the ijth Nano-Silica, i: 1 to 6 (1: control, 2: NS $0.05 \%$, 3: NS $0.10 \%$, 4: NS $0.15 \%, 5$ : NS $0.20 \%$, and bentonite $0.50 \%$ ). ij stands for a random error associated with the ijth observation and is assumed to be independently and normally distributed. 


\section{Results}

\subsection{Detection of Dietary Mycotoxins}

The control diets used in the current study were mainly detectable in different mycotoxins. Table 2 indicates the levels of mycotoxins in different stages of feeding.

Table 2. Mycotoxin concentration determined in the diets fed in the different stages of the trials.

\begin{tabular}{ccccc}
\hline Dietary Group & AFB1 (ppb/kg) & OA (ppb/kg) & T2 (ppb/kg) & FB (mg/kg) \\
\hline Starter & 35.33 & 120 & 74 & 120 \\
Grower & 37.25 & 173 & 88 & 135 \\
Finisher & 39.22 & 190 & 92 & 220 \\
\hline
\end{tabular}

AFB1: Aflatoxin B1. OA: Ochratoxin. T2: T2 Toxins. FB: Fumonisins.

\subsection{Growth Performance}

According to the results presented in Table 3, the BW of chickens fed diets supplemented with $0.20 \%$ NS showed a significant change compared with other treatment groups at the different stages of growing chickens at 14, 21, 28, and 35 days. The highest BW was recorded for NS at $0.20 \%$ compared with other treatments, followed by NS at $0.15 \%$.

Table 3. Effects of nanosilica and bentonite supplementation on the performances of male broiler chickens between 0 and 35 days of age.

\begin{tabular}{|c|c|c|c|c|c|c|c|c|}
\hline \multirow[b]{2}{*}{ Items } & \multicolumn{5}{|c|}{ Nanosilica Levels } & \multirow[b]{2}{*}{$\begin{array}{c}\text { Bentonite } \\
0.50 \%\end{array}$} & \multirow[b]{2}{*}{ SEM } & \multirow[b]{2}{*}{$p$-Values } \\
\hline & Control & $0.05 \%$ & $0.10 \%$ & $0.15 \%$ & $0.20 \%$ & & & \\
\hline & \multicolumn{8}{|c|}{ Body Weight (BW), g/bird } \\
\hline $7 \mathrm{~d}$ & 175.7 & 175.7 & 175.7 & 175.7 & 175.7 & 175.7 & 0.08 & ns \\
\hline $14 \mathrm{~d}$ & $419.3^{\mathrm{d}}$ & $429.3^{c}$ & $441.3^{b}$ & $441.7^{\mathrm{b}}$ & $451.3^{\mathrm{a}}$ & $416.0^{\mathrm{d}}$ & 1.50 & $<0.050$ \\
\hline $21 \mathrm{~d}$ & $844.0^{\mathrm{c}}$ & $873.3^{b}$ & $874.0^{\mathrm{b}}$ & $878.0^{\mathrm{b}}$ & $896.0^{a}$ & $848.7^{c}$ & 2.94 & $<0.050$ \\
\hline $28 \mathrm{~d}$ & $1397.7^{c}$ & $1395.3^{c}$ & $1398.3^{c}$ & $1465.0^{\mathrm{b}}$ & $1497.3^{a}$ & $1394.0^{c}$ & 3.39 & $<0.050$ \\
\hline $35 \mathrm{~d}$ & $1925.0^{\mathrm{d}}$ & $1977.0^{\mathrm{c}}$ & $1975.0^{\mathrm{c}}$ & $2032.3^{b}$ & $2061.0^{a}$ & $2013.7^{b}$ & 9.02 & $<0.050$ \\
\hline & \multicolumn{8}{|c|}{ Body Weight Gain (BWG), g/bird } \\
\hline $7-14 \mathrm{~d}$ & $244.3^{\mathrm{d}}$ & $253.7^{c}$ & $265.7^{b}$ & $266.0^{\mathrm{b}}$ & $275.7^{\mathrm{a}}$ & $240.3^{d}$ & 1.54 & $<0.050$ \\
\hline $15-21 d$ & $424.7^{c}$ & $444.3^{\mathrm{a}}$ & $432.7^{b}$ & $436.3^{b}$ & $445.0^{\mathrm{a}}$ & $432.7^{b}$ & 2.45 & $<0.050$ \\
\hline $22-28 d$ & $554.0^{\mathrm{c}}$ & $522.3^{e}$ & $524.3^{\mathrm{e}}$ & $587.3^{\mathrm{b}}$ & $601.3^{\mathrm{a}}$ & $545.7^{\mathrm{d}}$ & 2.84 & $<0.050$ \\
\hline $29-35 d$ & $527.3^{c}$ & $581.7^{\mathrm{b}}$ & $576.7^{\mathrm{b}}$ & $567.3^{\mathrm{b}}$ & $563.7^{\mathrm{b}}$ & $619.7^{\mathrm{a}}$ & 5.98 & $<0.050$ \\
\hline $7-35 d$ & $1750.0^{\mathrm{d}}$ & $1801.3^{c}$ & $1799.3^{c}$ & $1856.7^{b}$ & $1885.3^{\mathrm{a}}$ & $1838.0^{b}$ & 9.03 & $<0.050$ \\
\hline \multicolumn{9}{|c|}{ Feed Intake (FI), g/bird } \\
\hline $7-14 \mathrm{~d}$ & $281.0^{\mathrm{d}}$ & $288.0^{\mathrm{c}}$ & $282.7^{\mathrm{cd}}$ & $305.3^{\mathrm{a}}$ & $295.3^{b}$ & $277.0^{\mathrm{d}}$ & 1.93 & $<0.050$ \\
\hline $15-21 \mathrm{~d}$ & $570.3^{a}$ & $572.3^{a}$ & $567.3^{b}$ & $573.0^{\mathrm{a}}$ & $566.7^{b c}$ & $564.3^{c}$ & 0.99 & $<0.050$ \\
\hline $22-28 d$ & $832.0^{\mathrm{d}}$ & $844.3^{\mathrm{a}}$ & $838.0^{\mathrm{c}}$ & $840.7^{b}$ & $843.3^{a}$ & $845.3^{\mathrm{a}}$ & 0.73 & $<0.050$ \\
\hline $29-35 d$ & $1092.7^{b}$ & $1069.0^{\mathrm{c}}$ & $1062.7^{\mathrm{d}}$ & $1070.7^{\mathrm{c}}$ & $1056.0^{\mathrm{e}}$ & $1106.7^{\mathrm{a}}$ & 1.36 & $<0.050$ \\
\hline $7-35 d$ & $2775.3^{b}$ & $2772.7^{b}$ & $2750.0^{\mathrm{d}}$ & $2789.3^{a}$ & $2761.0^{c}$ & $2792.3^{a}$ & 3.19 & $<0.050$ \\
\hline \multicolumn{9}{|c|}{ Feed Conversion Ratio (FCR) } \\
\hline $7-14 \mathrm{~d}$ & $1.150^{\mathrm{a}}$ & $1.136^{\mathrm{a}}$ & $1.066^{\mathrm{b}}$ & $1.146^{\mathrm{a}}$ & $1.073^{\mathrm{b}}$ & $1.153^{\mathrm{a}}$ & 0.009 & $<0.050$ \\
\hline $15-21 \mathrm{~d}$ & $1.356^{\mathrm{a}}$ & $1.290^{c}$ & $1.316^{\mathrm{b}}$ & $1.313^{b}$ & $1.273^{\mathrm{d}}$ & $1.306^{\mathrm{bc}}$ & 0.007 & $<0.050$ \\
\hline $22-28 \mathrm{~d}$ & $1.500^{\mathrm{c}}$ & $1.620^{\mathrm{a}}$ & $1.603^{\mathrm{a}}$ & $1.430^{\mathrm{d}}$ & $1.403^{\mathrm{e}}$ & $1.550^{\mathrm{b}}$ & 0.008 & $<0.050$ \\
\hline $29-35 d$ & $2.083^{\mathrm{a}}$ & $1.840^{b c}$ & $1.840 \mathrm{bc}$ & $1.896^{\mathrm{b}}$ & $1.886^{\mathrm{b}}$ & $1.795^{\mathrm{c}}$ & 0.020 & $<0.050$ \\
\hline $7-35 d$ & $1.590^{\mathrm{a}}$ & $1.540^{\mathrm{b}}$ & $1.530^{b}$ & $1.503^{c}$ & $1.466^{\mathrm{d}}$ & $1.520 \mathrm{bc}$ & 0.008 & $<0.050$ \\
\hline
\end{tabular}

${ }^{a-e}$ Means within a row sharing different superscripts differ significantly $(p<0.05)$. SEM = Standard Error of Mean, BW= Body Weight, BWG = Body Weight Gain, FI = Feed Intake, FCR = Feed Conversion Ratio, and ns = Nonsignificant.

Table 3 shows that all NS treatments achieved higher values of BWG, compared with the control group, at the period of 7 to 14 days. The highest BWG was achieved with NS at $0.20 \%$. Additionally, at the period of $22-28$ days, the supplementation of $0.20 \%$ NS recorded the highest BWG. On the other hand, the addition of bentonite recorded the highest BWG 
at the period of 29-35 days compared with different treatments. Generally, at the overall period, the best BWG was obtained using $0.20 \%$ NS followed by $0.15 \%$ NS treatment.

Broiler chickens fed the diet with NS at $0.15 \%$ and $0.20 \%$ showed a significant increase in FI during 7-14 days of age compared with other treatments (Table 3). The diet with NS at $0.15 \%$ and $0.05 \%$ resembled the control's results and significantly higher than other treatments during 15-21 days. On the other hand, the addition of bentonite at 0.50 recorded the highest FI during 22-28 days. Feed intake was significantly increased with the addition of bentonite $0.50 \%$ during $29-35$ days compared to all the treatments. Regarding the overall FI (7-35 days), the addition of $0.15 \%$ of NS and $0.50 \%$ of bentonite showed a significant increase in FI compared with other treatments and the control group.

Statistical analysis indicated that NS at levels of $0.10 \%$ and $0.20 \%$ had a significant effect compared with all treatments on FCR during 7-14 days of age. Chickens receiving NS at $0.20 \%$ recorded a significant improvement of FCR compared with the control and other treatment groups during 15-21 days and 22-28 days of age. The best FCR value was recorded with treatment supplemented with commercial nanoclay (bentonite $0.50 \%$ ) followed by those having $0.05 \%$ and $0.10 \%$ of NS, compared with the control group at the period of 29-35 days of age. Considering the overall FCR, the addition of NS or bentonite improved FCR, and the best FCR was achieved with NS at $0.20 \%$, compared with other treatments $(p<0.05)$.

\subsection{Carcass Characteristics}

The data presented in Table 4 shows that no significant effects of dietary treatments on carcasses, abdominal fat, bursa, thymus, and relative organs weight (liver, heart, gizzard, and spleen) were observed.

Table 4. Effects of nanosilica and bentonite supplementation on eviscerated carcass and some internal organs of male broiler chickens at 35 days of age * (expressed as \% of body weight) ${ }^{*}$.

\begin{tabular}{|c|c|c|c|c|c|c|c|c|}
\hline Treatments & Carcass (\%) & Liver (\%) & Heart (\%) & Gizzard (\%) & Spleen $(\%)$ & Abd. Fat (\%) & Bursa (\%) & Thymus (\%) \\
\hline Control & 73.00 & 2.30 & 0.47 & 1.95 & 0.11 & 0.45 & 0.21 & 0.37 \\
\hline NS $0.05 \%$ & 73.33 & 2.31 & 0.48 & 2.17 & 0.14 & 0.42 & 0.22 & 0.30 \\
\hline NS $0.10 \%$ & 74.95 & 2.41 & 0.50 & 2.11 & 0.12 & 0.59 & 0.23 & 0.35 \\
\hline NS $0.15 \%$ & 72.47 & 2.25 & 0.60 & 2.17 & 0.14 & 0.67 & 0.22 & 0.39 \\
\hline NS $0.20 \%$ & 73.10 & 2.36 & 0.60 & 2.21 & 0.12 & 0.56 & 0.18 & 0.29 \\
\hline $\begin{array}{c}\text { Bentonite } \\
0.50 \%\end{array}$ & 74.14 & 2.11 & 0.62 & 1.93 & 0.13 & 0.46 & 0.24 & 0.29 \\
\hline SEM & 2.50 & 0.41 & 0.05 & 0.25 & 0.03 & 0.09 & 0.01 & 0.03 \\
\hline$p$-Values & ns * & ns & $\mathrm{ns}$ & $\mathrm{ns}$ & $\mathrm{ns}$ & $\mathrm{ns}$ & $\mathrm{ns}$ & ns \\
\hline
\end{tabular}

* The percentage of eviscerated carcass and some internal organs to live body weight. NS = Nanosilica, SEM = Standard Error Means, Abd. fat $=$ Abdominal fat, and $\mathrm{ns}^{*}=$ Nonsignificant. Values in each column are means of three replicates (ten birds each) for each treatment $(\mathrm{n}=6)$.

\subsection{Histological Findings}

Microscopic examination of different liver tissue sections from different groups revealed that the normal histomorphological structures of hepatic tissue were demonstrated in control samples (Figure 1a), including normally appearing blood vessels (star), portal areas, and radiating plates of intact hepatocytes with vesicular centrally situated nuclei (arrow). Mild degenerative changes were recorded in hepatocytes with dark pyknotic nuclei (arrow). Variable protective effects were demonstrated in different treated groups on morphological structures. However, the best records were found in nanosilica $0.20 \%$ (Figure 1e), nano-bentonite (Figure 1f), and nanosilica $0.15 \%$ (Figure 1d), respectively, with few scattered degenerated hepatocytes (arrows) and normal blood vessels as well as sinusoids-except mild dilatation of hepatic blood vessels-in NS 0.15\% samples (star, Figure 1d). Examined hepatic tissue sections of NS $0.05 \%$ showed the existence of focal periportal inflammatory cell infiltrations (star) with the proliferation of bile ducts (arrowhead), and few degenerated hepatocytes (arrow) (Figure 1b). Moreover, NS 0.10\% samples demonstrated marked dilata- 
tion and congestion of hepatic sinusoids (star) with minimal inflammatory cell infiltrates (Figure 1c). Number of lesion score of liver has been shown in Table 5.
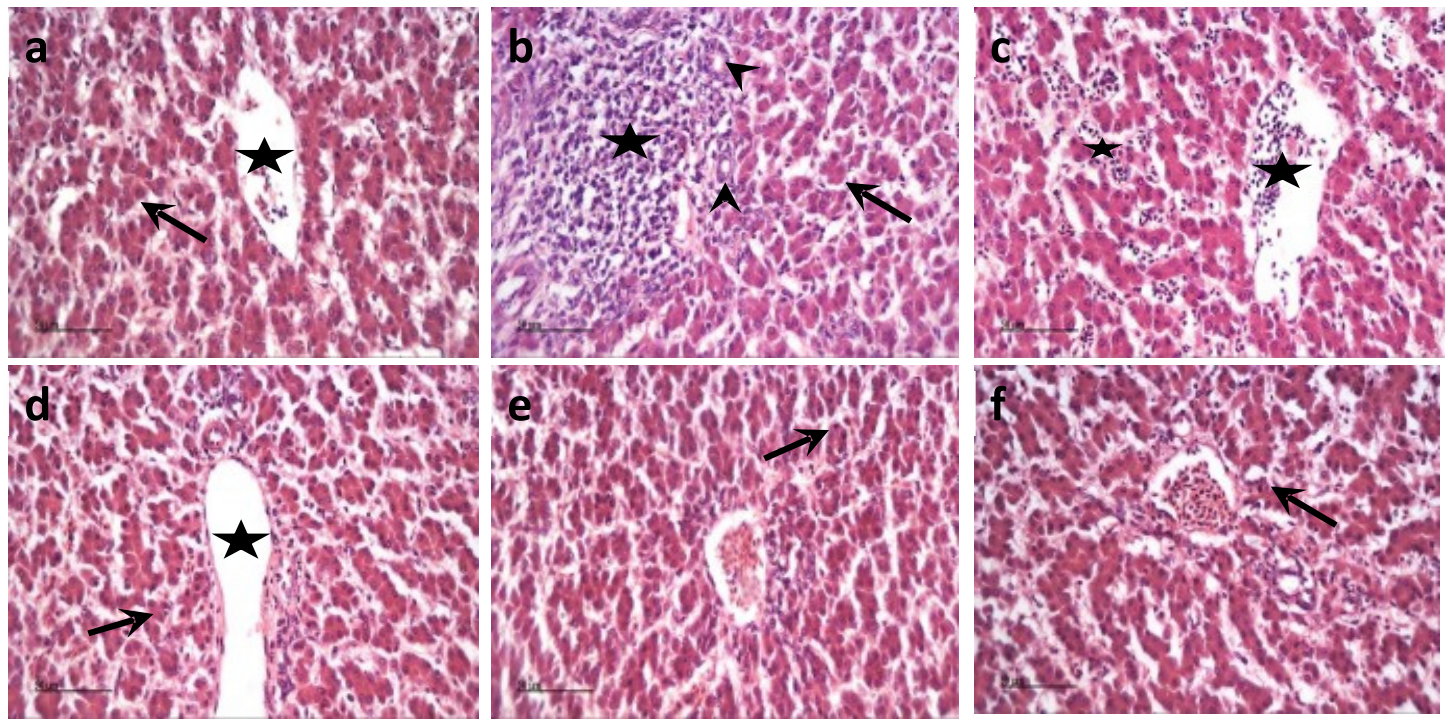

Figure 1. The hepatoprotective efficacy of nanosilica in different doses: (a) control normal group hepatic samples with normal morphological features of the hepatic parenchyma, (b) hepatic samples of nanosilica in the $0.05 \%$ administrated group, (c) hepatic samples of nanosilica in the $0.10 \%$ administrated group, (d) hepatic samples of nanosilica in the $0.15 \%$ administrated group, (e) hepatic samples of nanosilica in the $0.20 \%$ administrated group, and (f) hepatic samples of nano-bentonite administrated group. H\&E stain. X400. Scale bar: 50 microns.

Table 5. Efficacy of nanosilica and bentonite in the amelioration of the toxic effects of mycotoxins on liver lesion score.

\begin{tabular}{ccccc}
\hline Treatments & $\begin{array}{c}\text { Degenerative Changes } \\
\text { of Hepatocytes }\end{array}$ & $\begin{array}{c}\text { Inflammatory } \\
\text { CellsInfiltration }\end{array}$ & $\begin{array}{c}\text { Hepatic Vasculatures/ } \\
\text { Sinusoidal Diltation }\end{array}$ & $\begin{array}{c}\text { Proliferation of Bile } \\
\text { Ducts }\end{array}$ \\
\hline Control & + & - & - & - \\
NS $0.05 \%$ & + & ++ & - & ++ \\
NS $0.10 \%$ & + & + & +++ & - \\
NS $0.15 \%$ & + & - & + & - \\
NS $0.20 \%$ & + & - & - & - \\
Bentonite $0.50 \%$ & + & - & - \\
\hline
\end{tabular}

Recorded lesions were graded and scored according to [19]. Where (-) is nil, (+) mild, less than $15 \%$ of examined samples. (++) moderate (16-35\% of examined samples), (+++) severe (more than $35 \%$ of the examined samples).

\section{Discussion}

The European Commission [23] published maximum levels of several mycotoxins in the European Union (EU) as aflatoxin $20 \mathrm{ppb} / \mathrm{kg}$ of feed, ochratoxin $100 \mathrm{ppb} / \mathrm{kg}$ of feed, T2 toxins $250 \mathrm{ppb} / \mathrm{kg}$ of feed, and fumonisins $20 \mathrm{mg} / \mathrm{kg}$ of feed. All levels of mycotoxins in control diets used herein (Table 2) were above the maximum recommended level of the European Guidance values except the T2 toxins, and the highest toxin level was fumonisins, which promotes the use of different sources of silica as an adsorbent agent in broiler chickens' feed. It is well known that intoxication is caused by mycotoxins, and it is one of the most serious risks, especially for poultry. Moreover, quality deterioration and decrease in the commercial value of feed ingredients are all possible negative effects of their bioaccumulation. So, the use of anti-mycotoxin agents, particularly in the form of nanoparticles, may improve the growth rate and digestibility.

The enhancement of performance may be attributed to the ability of NS and bentonite to adsorb mycotoxins. Consequently, they improved feed utilization. Numerous studies reported that clay minerals bentonite in animal feed induces the decrease of the harmful impacts of mycotoxins in vivo [24]. Formerly, "Ref. [25]" reported that supplementation 
of diets with two types of bentonites (clinoptilolite and zeolite) at $1 \%$ each as potential binders of three mycotoxins, aflatoxin, ochratoxin, and T2 toxin, present in broilers' diets (at levels not exceeding the EU maximum) exerted more prominent effects on the growth performance and GIT function of broiler chickens. Similarly, dietary nano hydrated magnesium aluminum silicate supplementation resulted in more pronounced changes in broiler chicken growth and digestive function than the traditional hydrated magnesium aluminum silicate equivalent [26]. These results may be attributed to the beneficial properties of nanosilica: high adsorbent capacity, the high surface area of layers, and the charge which binds different mycotoxins. In the present study, mycotoxins in the studied feed were overcome by nanosilica adsorbents with unique plate structures, large specific surface areas, excellent stability, and a wide range of functionalities, which could be used as multi-mycotoxin binders to mitigate the negative effects on broiler chickens' diets. The capacity of nanosilica to adsorb mycotoxins may be responsible for the increased BWG. As a result, feed consumption and body weight increased. "Ref. [7]" investigated diets containing hydrated sodium calcium aluminum silicate at a level of $0.30 \%$ as one of the physical detoxifiers that increased the average daily gain of broiler chickens. "Ref. [27]" reported that the greatest weight gain was observed by supplementing nanoclay to turkey feed. Furthermore, "Ref. [28]" suggested that sodium silicate improved the average daily gain of broiler chickens at a level of $0.50 \%$. The same trend was obtained by [29] who reported that the inclusion of silicate minerals in the diets of broiler chickens improved the weight gain, and they explained that this improvement may be due to the action of silicate minerals. As a result, increasing the digestibility of some nutrients while lowering the GIT passage rate lengthens the time nutrients are digested.

In this respect, "Ref. [30]" reported that the FI of a treated group with a local mycotoxin binder was significantly higher than that of the control group, leading to improved performance. "Ref. [31]" found that hydrated sodium calcium aluminosilicates in broiler diets ameliorate the decreased feed intake and increased weight gain at $2 \mathrm{mg} / \mathrm{kg}$ of AFB1, whereas $0.2 \%$ SO partially recovered the impaired growth performance. The improvement of FCR may be due to the improvement of the enzymatic activity of GIT by raising fluids' pH and decreasing the viscosity of digesta in the digestive tract of poultry. The findings of the present study agree with those of [27], who reported that the addition of $0.50 \%$ nanoclay as an adsorbent agent of mycotoxins in the diets of turkey improved FCR compared with the control group. Furthermore, "Ref. [32]" recorded that FCR was significantly improved with the addition of sodium bentonite at $0.5 \%$. Similarly, "Ref. [33]" incorporated zeolite with a nanostructure at $0.25 \%$ and $1 \%$ in the broiler chickens' diet contaminated with $500 \mathrm{ppb}$ aflatoxin and reported a reduction of toxic effects of aflatoxin on the growth performance.

The present result agreed well with that of [34], who discovered that the experimental therapies, which included two forms of bentonites in broiler chicken diets, had no statistically significant differences in carcass yield and relative weight of heart, spleen, liver, bursa of Fabricius, and gizzard. However, "Ref. [35]" found that supplemented sodium bentonite and coumarin to the aflatoxin-contaminated rabbits' diet improved the carcass characteristics and live body weight.

Mycotoxins can exert histopathological changes that can interfere with broiler growth rate. Therefore, the addition of nanosilica and bentonite showed protective effects on the histopathological changes in liver sections, leading to the enhancement of enzyme secretion and improved performance. Agreeing with this study, "Ref. [36]" concluded that the addition of silica to diets containing AFB1 significantly reduced the incidence and severity of the hepatic histopathology changes associated with aflatoxicosis and the amount of AFB1 residue in the liver and improved performance. In another study, "Ref. [31]" proved showed that treatment by Hydrated Sodium Calcium Aluminosilicates (HSCAS) in broiler diets ameliorated the negative effects of AFB on growth performance and liver damage. Accordingly, Ref. [37] showed that the addition of bentonite was more effective in preventing histopathological effects from aflatoxicosis, compared with activated charcoal 
or fuller's earth. However, "Ref. [32]" revealed that no mycotoxins were detected in the examined liver and breast muscles when two types of bentonites in broiler diets were used. Additionally, "Ref. [35]" investigated that no histopathological changes were observed in the liver tissues of rabbits fed with aflatoxin-contaminated diets containing sodium bentonite and coumarin. Furthermore, the current study agreed with [30], who found that the addition of local mycotoxin binder to broiler diets showed a protective effect on liver tissue and improved performance. "Ref. [38]" reported that the addition of bentonite to the contaminated broiler diets with aflatoxin and fumonisin showed a reduction in the multifocal and varied cytoplasmatic vacuolization through the reduction of the incidence and severity of the hepatic histopathology changes associated with aflatoxicosis.

\section{Conclusions}

This study showed that the contaminations of mycotoxins in feed can affect the growth rate of broilers. It is necessary to use adsorbent agents, such as bentonite or silicate and especially in the form of nanosilica, which can be more active to minimize the harmful effects of mycotoxins. Moreover, the study addresses the prevention and control strategies of mycotoxins using clay minerals in the form of nanosilica and bentonite. It could be concluded that the addition of nanosilica and bentonite improved the performance and the health of broiler chickens at $0.20 \%$ and $0.50 \%$ levels, respectively. The findings suggest that there is a need to conduct more research in the field using nanomaterials as adsorbent agents for mycotoxins. The obtained results can be implemented in different areas, including the utilization of rice husks as a source of nanosilica acting as an adsorbent agent of mycotoxins to improve the performance of broiler chickens.

Author Contributions: Conceptualization, A.A.G., K.E.M.E.M. and M.O.A.-E.; methodology, K.E.M.E.M. and A.-E.A.A.R.; data curation, A.-E.A.A.R.; writing - original draft preparation, A.A.G. and K.E.M.E.M.; writing-review and editing, A.A.G. and M.O.A.-E.; supervision, M.A.K.; hepatological analyzed. All authors have read and agreed to the published version of the manuscript.

Funding: This research received no external funding.

Institutional Review Board Statement: The feeding trial was approved by the Institutional Animal Care and Use Committee of Cairo University with the reference number CU II F 321.

Data Availability Statement: Data are available if requested.

Conflicts of Interest: All the authors declare that they have no competing interests.

\section{References}

1. Bryden, W.L. Mycotoxin contamination of the feed supply chain: Implications for animal productivity and feed security. Anim. Feed Sci. Technol. 2012, 173, 134-158. [CrossRef]

2. Horky, P.; Skalickova, S.; Baholet, D.; Skladanka, J. Nanoparticles as a solution for eliminating the risk of mycotoxins, Nanomaterials. J. Nanomater. 2018, 8, 727. [CrossRef]

3. Wang, Y.; Zhao, C.; Zhang, D.; Zhao, M.; Zheng, D.; Peng, M.; Cui, Z. Simultaneous degradation of aflatoxin B1 and zearalenone by a microbial consortium. Toxicon 2018, 146, 69-76. [CrossRef] [PubMed]

4. Vila-Donat, P.; Marín, S.; Sanchis, V.; Ramos, J.A. New mycotoxin adsorbents based on tri-octahedral bentonites for animal feed. Anim. Feed Sci. Technol. 2019, 255, 114228. [CrossRef]

5. Huwig, A.; Freimund, S.; Käppeli, O.; Dutler, H. Mycotoxin detoxication of animal feed by different adsorbents. Toxicol. Lett. 2001, 122, 179-188. [CrossRef]

6. Lozano, M.C.; Diaz, G.J. Microsomal and cytosolic biotransformation of aflatoxin B1 in four poultry species. Br. Poult. Sci. 2006, 47, 734-741. [CrossRef] [PubMed]

7. Zhu, Y.; Hassan, Y.I.; Watts, C.; Zhou, T. Innovative technologies for the mitigation of mycotoxins in animal feed and ingredients. A review of recent patents. Anim. Feed Sci. Technol. 2017, 216, 19-29. [CrossRef]

8. Arana, S.; Dagli, M.; Sabino, M.; Tabata, Y.A.; Rigolino, M.G.; Hernandez-Blazquez, F.J. Evaluation of the efficacy of hydrated sodium aluminosilicate in the prevention of aflatoxin-induced hepatic cancer in rainbow trout. Pesqui. Veterinária Bras. 2011, 31, 751-755. [CrossRef]

9. Pozzo, M.D.; Viegas, J.; Kozloski, G.V.; Stefanello, C.M.; Silveira, A.M.; Bayer, C.; Santurio, J.M. The effect of mycotoxins ad-sorbents beta glucans or montmorillonite on bovine ruminal fermentation in vitro. Acta Sci.Vet. 2016, 44, 1342. 
10. Swain, P.S.; Rao, S.B.N.; Rajendran, D.; Dominic, G.; Selvaraju, S. Nano zinc, an alternative to conventional zinc as animal feed supplement: A review. Anim. Nutr. 2016, 2, 134-141. [CrossRef]

11. Jeevanandam, J.; Barhoum, A.; Chan, Y.S.; Dufresne, A.; Danquah, M.K. Review on nanoparticles and nanostructured materials: History, sources, toxicity, and regulations. Beilstein J. Nanotechnol. 2018, 9, 1050-1074. [CrossRef]

12. Wagner, S.; Gondikas, A.; Neubauer, E.; Hofmann, T.; von der Kammer, F. Spot the Difference: Engineered and Natural Nanoparticles in the Environment-Release, Behavior, and Fate. Angew. Chem. Int. Ed. 2014, 53, 12398-12419. [CrossRef] [PubMed]

13. Bailey, C.A.; Latimer, G.W.; Barr, A.C.; Wigle, W.L.; Haq, A.U.; Balthrop, J.E. Efficacy of Montmorillonite Clay (NovaSil PLUS) for Protecting Full-Term Broilers from Aflatoxicosis. J. Appl. Poult. Res. 2006, 15, 198-206. [CrossRef]

14. Xia, M.S.; Hu, C.H.; Xu, Z.R. Effects of copper-bearing montmorillonite on growth performance, digestive enzyme activities, and intestinal microflora and morphology of male broilers. Poult. Sci. 2004, 83, 1868-1875. [CrossRef] [PubMed]

15. Pappas, A.C.; Zoidis, E.; Theophilou, N.; Zervas, G.; Fegeros, K. Effects of palygorskite on broiler performance, feed technological characteristics, and litter quality. Appl. Clay Sci. 2010, 49, 276-280. [CrossRef]

16. Wu, Q.J.; Zhou, Y.M.; Wu, Y.N.; Zhang, L.L.; Wang, T. The effects of natural and modified clinoptilolite on intestinal barrier function and immune response to LPS in broiler chickens. Vet. Immunol. Immunopathol. 2013, 153, 70-76. [CrossRef]

17. Ouhida, I.; Perez, J.F.; Gasa, J.; Puchal, F. Enzymes ( $\beta$-glucanase and arabinoxylanase) and/or sepiolite supplementation and the nutritive value of maize-barley-wheat based diets for broiler chickens. Br. Poult. Sci. 2000, 41, 617-624. [CrossRef]

18. Bancroft, J.D.; Gamble, M. Theory and Practice of Histological Techniques. Histopathology 1990, 34, 384-385. [CrossRef]

19. Al-Sayed, E.; Michel, H.E.; Khattab, M.A.; El-Shazly, M.; Singab, A.N. Protective Role of Casuarinin from Melaleuca leucadendra against Ethanol-Induced Gastric Ulcer in Rats. Planta Med. 2020, 86, 32-44. [CrossRef] [PubMed]

20. Carmona, V.B.; Oliveira, R.M.; Silva, W.T.L.; Mattoso, L.H.C.; Marconcini, J.M. Nanosilica from rice husk: Extraction and characterization. Ind. Crops Prod. 2013, 43, 291-296. [CrossRef]

21. Statistical Analysis System (SAS). SAS User's Guide: Statistics; Version 9.1; SAS Inst. Inc.: Cary, NC, USA, 2010.

22. Duncan, D.B. Multiple Range and Multiple F Tests. Biom. JSTOR 1955, 11, 1. [CrossRef]

23. European Commission (EC) No 435. Amending Annex I to Council Regulation (EC) No 1234/2007 (Single CMO Regulation) as Regards Certain Codes of the Combined Nomenclature. In Single Common Market Organisation; Nomos Verlagsgesellschaft mbH and Co. KG: Baden, Germany, 2009; pp. 1032-1033. [CrossRef]

24. Chkuaseli, A.; Khutsishvili, M.M.; Chagelishvili, A.; Natsvaladze, K.; Lashkarashvili, T. Chagelishvili, G. Application of new mycotoxin adsorbent-bentonite clay "Askangel" in poultry feed. Ann. Agrar. Sci. 2016, 14, 295-298. [CrossRef]

25. Parizadian, K.B.; Shams, S.M.; Hassani, S.; Mostafalo, Y. Effects of physical sizes of clinoptilolite on protein efficiency ratio, intestinal morphology and growth indices of broilers. Iran. J. Appl. Anim. Sci. 2014, 4, 165-172.

26. Du, M.; Chen, Y.; Cheng, Y.; Wen, C.; Wang, W.; Wang., A. A comparison study on the effects of dietary conventional and ultra-fine ground palygorskite supplementation on the growth performance and digestive function of broiler chickens. Appl. Clay Sci. 2019, 181, 105211. [CrossRef]

27. Lala, A.O.; Oso, A.O.; Ajao, A.; Idowu, O.M.; Oni, O.O. Effect of supplementation with molecular or nano-clay adsorbent on growth performance and haematological indices of starter and grower turkeys fed diets contaminated with varying dosages of aflatoxin B1. Livest. Sci. 2015, 178, 209-215. [CrossRef]

28. Wu, Q.J.; Wang, L.C.; Zhou, Y.M.; Zhang, J.F.; Wang, T. Effects of clinoptilolite and modified clinoptilolite on the growth performance, intestinal microflora, and gut parameters of broilers. Poult. Sci. 2013, 92, 684-692. [CrossRef]

29. Katouli, M.S.; Boldaji, F.; Dastar, B.; Hassani, S. The effect of dietary silicate minerals supplementation on apparent ileal digestibility of energy and protein in broiler chickens. Int. J. Agric. Biol. 2012, 14, 299-302.

30. Saleemi, M.K.; Ashraf, K.; Gul, S.T.; Naseem, M.N.; Sajid, M.S.; Mohsin, M. Toxicopathological effects of feeding aflatoxins B1 in broilers and its ameliosration with indigenous mycotoxin binder. Ecotoxicol. Environ. Saf. 2020, 187, 109712. [CrossRef] [PubMed]

31. Zhao, J.; Shirley, R.B.; Dibner, J.D.; Uraizee, F.; Officer, M.; Kitchell, M.; Vazquez-Anon, M.; Knig, C.D. Comparison of hydrated sodium calcium aluminosilicate and yeast cell wall on counteracting aflatoxicosis in broiler chicks. Poult. Sci. 2010, 89, 2147-2156. [CrossRef]

32. Pasha, T.N.; Farooq, M.U.; Khattak, F.M.; Jabbar, M.A.; Khan, A.D. Effectiveness of sodium bentonite and two commercial products as aflatoxin absorbents in diets for broiler chickens. Anim. Feed Sci. Technol. 2007, 132, 103-110. [CrossRef]

33. Shabani, A.; Dastar, B.; Khomeiri, M.; Shabanpour, B.; Hassani, S. Response of Broiler Chickens to Different Levels of Nanozeolite During Experimental Aflatoxicosis. J. Biol. Sci. 2010, 10, 362-367. [CrossRef]

34. Pappas, A.C.; Tsiplakou, E.; Georgiadou, M.; Anagnostopoulos, C.; Markoglou, A.N.; Liapis, K. Bentonite binders in the presence of mycotoxins: Results of in vitro preliminary tests and an in vivo broiler trial. Appl. Clay Sci. 2014, 99, 48-53. [CrossRef]

35. Hassan, A.A.; Hafsa, S.H.A.; Elghandour, M.M.M.Y.; Reddy, P.R.K.; Monroy, J.C.; Salem, A.Z.M. Dietary Supplementation with sodium bentonite and coumarin alleviates the toxicity of aflatoxin B1 in rabbits. Toxicon 2019, 171, 35-42. [CrossRef]

36. Denli, M.; Blandon, J.C.; Guynot, M.E.; Salado, S.; Perez, J.F. Effects of dietary AflaDetox on performance, serum biochemistry, histopathological changes, and aflatoxin residues in broilers exposed to aflatoxin B1. Poult. Sci. 2009, 88, 1444-1451. [CrossRef] [PubMed]

37. Mgbeahuruike, A.C.; Ejioffor, T.E.; Christian, O.C.; Shoyinka, V.C.; Karlsson, M.; Nordkvist, E. Detoxification of AflatoxinContaminated Poultry Feeds by 3 Adsorbents, Bentonite, Activated Charcoal, and Fuller's Earth. J. Appl. Poult. Res. 2018, 27, 461-471. [CrossRef]

38. Miazzo, R.; Peralta, M.F.; Magnoli, C.; Salvano, M.; Ferrero, S.; Chiacchiera, S.M.; Carvalho, E.C.; Rosa, C.A.; Dalcero, A. Efficacy of sodium bentonite as a detoxifier of broiler feed contaminated with aflatoxin and fumonisin. Poult. Sci. 2005, 84, 1-8. [CrossRef] 